\title{
A STUDY ON ADVERSE DRUG REACTIONS AND THEIR RISK FACTORS OF ANTI- ASTHMATIC AGENTS AMONG GARMENTS DUST-INDUCED ASTHMATIC PATIENTS IN MANCHESTER OF SOUTH INDIA
}

\author{
MUTHUKUMAR A*, SUNDARA GANAPATHY R \\ ${ }^{1}$ Department of Pharmacy, Faculty of Pharmacy, Karpagam Academy of Higher Education, Coimbatore - 641 021, Tamil Nadu, India. \\ ${ }^{2}$ Department of Pharmacology, Krupanidhi College of Pharmacy, Bengaluru - 560 035, Karnataka, India. Email: mkpharmacologist@gmail.com
}

Received: 01 March 2018, Revised and Accepted: 15 May 2018

\section{ABSTRACT}

Objective: Adverse drug reactions (ADRs) are well known to occur with any class of drugs when used in normal doses for the management of diseases. The main aim of the study was to detect and analyze ADRs in patients with bronchial asthma in a Coimbatore zone.

Methods: This was an observational, voluntary reporting study. The study was conducted in and around Coimbatore. Samples are collected in all age groups. We are taken support of "Suspected ADR" reporting form from Indian pharmacopoeia commission to collect samples.

Results: A total of 1163 ADRs were reported by patients during the study period with male predominance over female. The average age of the patients in the study was found to be 30-60 years. The majority of ADR occurred in the age group 30-60 years, the average duration of bronchial asthma in this study was found to be 3 years. The most commonly occurred ADRs were beclomethasane-induced seizures, salbutamol-induced tremor, anorexia, and nausea, and nausea, salmeterol-induced tremor, and montelukast-induced angioedema were also common.

Conclusion: An ADR due to oral anti-asthmatic is a frequent problem. Few multicenter studies are needed for a strong anti-asthmatic drug ADRs database in India.

Keywords: Adverse drug reactions, Anti-asthmatic agents, Garment dust, South Manchester.

(C) 2018 The Authors. Published by Innovare Academic Sciences Pvt Ltd. This is an open access article under the CC BY license (http://creativecommons. org/licenses/by/4. 0/) DOI: http://dx.doi.org/10.22159/ajpcr.2018.v11i9.25561

\section{INTRODUCTION}

Prescriber's knowledge about the pharmacodynamic and pharmacokinetics aspects of medicines and their interaction with normal aging physiology is critical in the management of asthma. The knowledge is needed to minimize and even avoid the potentially the adverse effects of seizures and side effects associated with the anti-asthmatics drug [1,2]. It is well known and obvious that adverse reactions to drugs can occur with any class of drug as the patient consumes any drugs or the various disease conditions. According to the World Health Organization, the adverse drug reactions (ADRs) can be defined as 'a response to a drug that is noxious and unintended and occurs at doses normally used in human or the prophylaxis, diagnosis and treatment of disease, or modification of physiological function [3-5]. The female gender age and multiple medications and the physiological state of renal and liver function, breastfeeding, pregnancy, and alcohol intake are considered as important risk factors of ADRs [6]. ADRs are considered as one of the most important leading cause of mortality in many countries. Adverse drug effects not only accounts for significant morbidity and mortality but can also lead to increase in the length of hospital stay and health-care cost. The overall rate of adverse effects is estimated to be $6.5 \%$, and $28 \%$ of these, ADRs are preventable. One of the meta-analyses found an adverse effect rate of $6.7 \%$ among hospitalized patients $[7,8]$.

\section{METHODS}

\section{Study type}

This study was based on those patients who experienced on adverse reaction to medicine use and visited the outpatient department and ultimately reported to clinical pharmacist for drug information center.

\section{Study approval}

This study was approved by the Institutional Human Ethics Committee of Karpagam Faculty of Medical Sciences and Research Coimbatore (IHEC/114/Pharmacy/09.2017)

\section{Study duration}

This study was carried out for a period of 6 months from December 2016 to June 2017. The data for the study were collected from the patients who had an ADR by personal interview. Past history of medication use, which is generally obtained from past prescription.

\section{Inclusion criteria}

Patients with adverse effects, of any age of either sex, have of reported to the clinical pharmacist from the outpatient department of various hospitals in Coimbatore zone.

\section{Exclusion criteria}

The ADRs that due to medication errors, overprescribing, overdosing/ excess consumption, drug-drug interaction, drug-food interaction, and drug interaction with a use of alternative system of medicine were excluded from the study.

\section{RESULTS}

A total of 1163 patient case sheets were reviewed, 252 ADRs were reported by patients during the study period. Incidence of ADRs occurrence was higher in male patients (77\%) than the female patients $(23 \%)$. The age range of patients in the study was found to be years 30-60. The duration of work-related asthma in the study was 3 months. The most of the patients in our study received 11-15 drugs during their hospital stay. In our study, the common drugs of anti-asthmatics are salbutamol, beclomethasone, and salmeterol, and combination therapy is ipratropium + salbutamol, beclomethasone + salbutamol, and salmeterol + fluticasone. Out of 
1163 patients, 48 were given with salbutamol; dose varied from $4 \mathrm{mg} /$ day up to $8 \mathrm{mg} /$ day. Of them, a total of 12 patients were reported one or more adverse effects after use of this drug; among them, there were $33.3 \%$ incidence of seizures, $10.5 \%$ incidence of tremor, $17.6 \%$ of anorexia, and $5.2 \%$ incidence of nausea, $15.7 \%$ of anxiety, $5.2 \%$ of gastric, and $5.2 \%$ of headache. A total of 15 patients were given with beclomethasone in our study group; dose varied from 600 to $800 \mathrm{mcg} /$ day. Among them, 33.3\% of patients had symptoms of seizures (tremor, palpitation, vertigo, and dizziness) and $2(16.6 \%)$ patients were complained about palpitation after the use of beclomethasone. Hence, a total of 130 patients were complained about adverse event due to beclomethasone use. A total of 24 patients were given salmeterol combination with salbutamol for controlling workrelated asthma. Among them, 28.5\% patients were tremor and anorexia. One of them had complained about angioedema. It was occur in the dose of $2 \mathrm{mg} /$ day. The patients were given with combinations they are beclomethasone + salbutamol for 15 patients, salmeterol + fluticasone 20 patients, and here beclomethasone + salbutamol caused bronchospasm ADRs in $7(46.6 \%)$. Patient's seizures, totally 252 patients were reported about ADR, when using beclomethasone + salbutamol total 15 patients were reported adverse effects and using salmeterol + fluticasone total 20 patients were reported in Table 1 .

The present study was analyzed the statistical parameter by GraphPad Prism online calculator and observed the drug-induced ADRs such as palpitation, paradoxical bronchospasm, sweating, anorexia, and seizure were reported in Table 2.

\section{DISCUSSION}

The present study has reported the incidence and attempted to profile suspected ADRs due to anti-asthmatic drug in the asthmatic OPD setting in the informed consent. Bronchospasm is the most common adverse events reported in most of the drug utilization studies, but our studies aim for the common adverse events due to oral anti-asthmatic drugs only [9]. Hence, it has tremor as the most common ADR, not seizures. In a study conducted in Italy, 148,289 ADR reports have been collected and, of these, $3416(2.3 \%)$ were due to antiasthmatic agents. The most reported serious ADRs were severe seizures (about $50 \%$ of serious ADR report) mainly caused by beclomethasone and salbutamol [10]. Regarding fluticasone and bronchodilators, gastrointestinal system was the most frequently affected site. Anorexia and tremor were the most common adverse effect reported by patients to doctors followed by salmeterol. Beclomethasone alone or its combination with salbutamol caused a few incidences of seizures; all of them were occurred if beclomethasone was used with dose of $2 \mathrm{mg} /$ day or more. Salbutamol-induced tremor occurred only if it was used in dose more than $10 \mathrm{mg}$ /day. Incidence of tremor was also common with the use of salmeterol, as expected from its mechanism of action and salmeterol combination produced more frequent incidents of tremor [11-14]. The study has found a few cases of pedal angioedema with montelukast use, in dose of $10 \mathrm{mg}$. Higher than $10 \mathrm{mg}$ dose for leukotriene antagonist was not used. The patients who reported angioedema, their dose for montelukast was reduced to $7.5 \mathrm{mg} /$ day, which did not, produced pedal angioedema to any of the subjects. In our study, out of 11 adverse effects, $77 \%$ were reported by male and $23 \%$ were reported by female patients. There were no serious events recorded, may be due to insulin was kept out of the measurement, which is the most common agent to cause fatal seizures. Most of the adverse events were managed by reducing the dose of the drug, and in some cases by stopping the drug such as stopping beclomethasone if patients had prolonged palpitation [15]. Adverse effects can perhaps also be reduced using less medication and with adequate knowledge of drug interactions. An anti-asthmatic drug ADR database builtup on the basis of such studies conducted across multiple centers, though active collaboration of pulmonologist and pharmacologist can be a worthy long-term goal in the Indian context $[16,17]$.

\section{CONCLUSION}

ADRs due to oral anti-asthmatic drug are a very frequent problem. Although they are not likely to be life-threatening, they can cause various types of

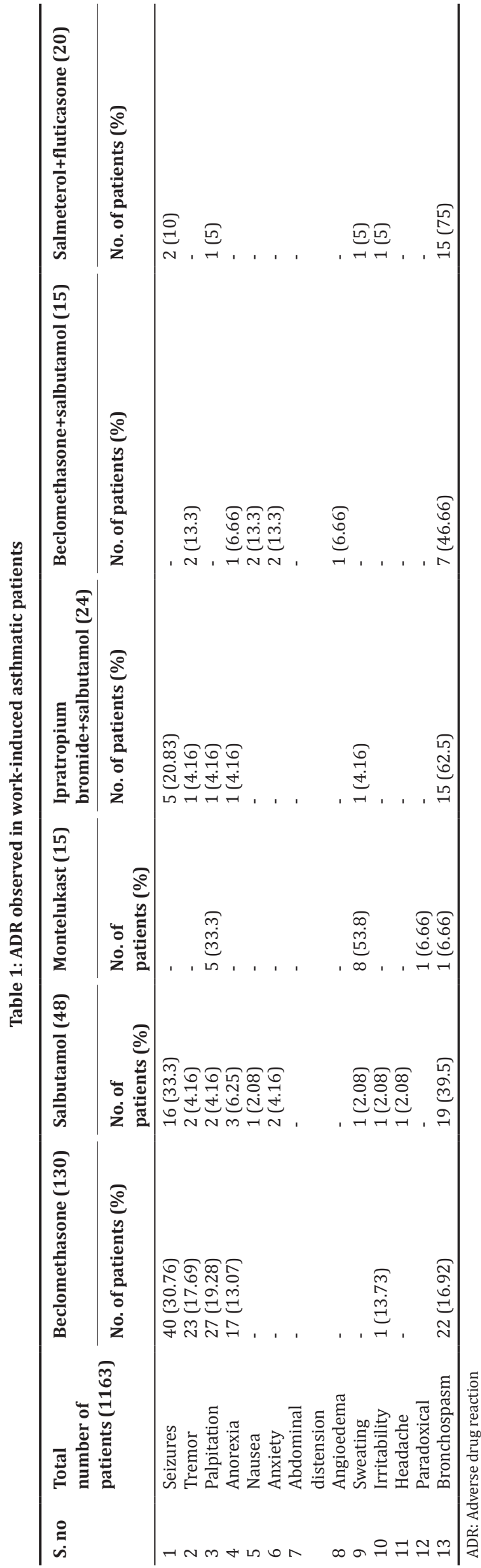


Table 2: Statistical analysis of observed ADR in anti-asthmatic agents

\begin{tabular}{lllll}
\hline Observed ADR & Mean & SD & SEM & Confidence interval (95\%) \\
\hline Seizures & 15.75 & 17.25 & 8.63 & $-1174.70-1119.80$ \\
Tremor & 5.20 & 9.98 & 4.47 & $-1170.20-1145.40$ \\
Palpitation & 7.20 & 11.21 & 5.01 & $-1169.72-1141.88$ \\
Anorexia & 4.20 & 7.26 & 3.25 & $-1167.81-1149.79$ \\
Bronchospasm & 13.17 & 7.81 & 3.19 & $-1158.03-1141.64$ \\
\hline
\end{tabular}

ADR: Adverse drug reaction, SD: Standard deviation, SEM: Standard error of the mean

discomforts in many patients. Few large multicenter studies on this matter need to be done to build a strong anti-asthmatic drug-ADR database.

\section{ACKNOWLEDGMENT}

We express a very humble thanks to our beloved chairman Dr. R. VasanthaKumar, Karpagam Group of Institutions, Coimbatore and Dr. S. Mohan Principal, Karpagam College of Pharmacy, Coimbatore.

\section{REFERENCES}

1. Raut AL, Patel P, Patel C, Pawar A. Preventability, predictability and seriousness of adverse drug reactions amongst medicine inpatients in a teaching hospital: A prospective observational study. Int J Pharm Chem Sci 2012;1:1293-8

2. Shareef J, Fernandes J, Samaga L, Khader SA. A study on adverse drug reaction in hospitalized patients with diabetes mellitus in a multispeciality teaching hospital. Asian J Pharm Clin Res 2016;9:114-7.

3. Padmaja SY, Palaniswamy S. A study on assessment, monitoring and documentation of adverse drug reactions. Int J Pharm Teach Pract 2012;3:253-6.

4. Shamna S, Dilip C, Ajmal M, Linu MP, Shinu C, Jafer CP, et al. A prospective study on adverse drug reactions of antibiotics in a tertiary care hospital. Saudi Pharm J 2014;22:303-8.

5. Bhabhor PH, Patel TK, Vahora R, Patel PB, Desai N. Adverse drug reactions in a tertiary care teaching hospital in India: Analysis of spontaneous reported cases. Int J Basic Clin Pharmacol 2014;3:1078-85.

6. Roy K, Divya S, Nadig P, Prakash B. Monitoring and analysis of adverse drug reactions in a private tertiary care teaching hospital. Asian J Pharm Clin Res 2015;8:335-7.

7. Swamy S, Bhanu P, Nadig P, Murali M, Shetty M. Profile of suspect adeverse drug reactions in a teaching tertiary care hospital. Hosp J Pharmacol Clin Toxicol 2013;1:1005.
8. Mrugank BP, Hareesha RP. Prospective observational, non-randomized, parallel sequence study for assessment of adverse drug reactions due to chemotherapeutic treatment in different types of cancer patients. Int $\mathbf{J}$ Parm Sci Res 2013;4:386-91

9. Ahmad S, Ismail NE. A qualitative study exploring the impact of stigma in the lives of adult Asthma patients in Selangor Malaysia. Int J Pharm Pharm Sci 2015;7:373-535.

10. Ramanath KV, Ramesh S. A study on assessment of adverse drug reactions in tuberculosis patients. Am J Pharm Tech Res 2012;2:585-91.

11. Giner J, Roura P, Torres B, Burgos F, Castillo D, Tarragona E, et al. Knowledge, attitudes and preferences among Spanish community pharmacists regarding inhaled therapy the optim pharmacy study. Int J Pharm Pharm Sci 2016;8:53-60.

12. Current Pharmacovigilance Scenario in India, Uppsala Reports 57-Uppsala Monitoring Centre.

13. Kumar YS. Study of drug utilization pattern of antiseizures agents in a south Indian tertiary care teaching hospital. Indian J Pharmacol 2012;44:210-4.

14. Maheshwari P, Ravichandiran V, Kumar KB, Sreelekha KV, Baig TS, Shahel SN. Prescribing patterns of antibiotics in paediatrics for respiratory tract infections/disorders in tertiary care hospital. Asian J Pharm Clin Res 2015;8:259-61.

15. Deb T, Charabarty A, Ghosh A. Adverse drug reaction in Type 2 diabetes mellitus patients on oral anti diabetic drugs in a diabetes OPD of a tertiary care teaching hospital in the eastern India.Int J Med Sci Public Health 2017;6:1-4.

16. Triller DM, Clause SL, Hamilton RA. Risk of adverse events by patients destination after hospital discharge. Am J Health Syst Pharm 2005;62:367-9.

17. Mohamed HA, Al-Jaber MM, Al-Hamadani Z, Khmour HY, Al-Lenjawi BA, Schlogl JM. Prevalence of postnatal depression and associated risk factors among south Asian mothers living in a newly developing country. Asian J Pharm Clin Res 2016;9:57-61. 